\title{
ARTHROSCOPIC ASSESSMENT OF THE WRIST WITH KIENBÖCK'S DISEASE
}

\author{
AVALIAÇÃO ARTROSCÓPICA DE PUNHO COM \\ DOENCุA DE KIENBÖCK
}

\author{
Guilherme Augusto Silva Amariz ${ }^{1}$, Maria Virginia Arranz Abreu ${ }^{1}$, Bruno Azevedo Veronesi ${ }^{1}$, Marcelo Rosa de Rezende ${ }^{1}$ \\ 1. Grupo de Mão e Microcirurgia, Instituto de Ortopedia e Traumatologia, Hospital das Clinicas (HC-FMUSP), Faculdade de Medicina, Universidade de São Paulo, São Paulo, SP, Brazil.
}

\section{ABSTRACT}

Objective: Treatment of Kienböck's disease is challenging and the variability of results, despite the surgical technique, shows that there must be other aspects that can influence outcomes. The objective of this study is determine, through arthroscopic approach, the pattern of impairment of the carpal bones in Lichtman stage III patients. Method: Wrist arthroscopy was performed in patients with symptoms and evidence of lunate necrosis on $x$-rays, with signs of $3 \mathrm{~A}$ and $3 \mathrm{~B}$ stages. The Outerbridge classification was used to grade the articular status of the carpal bones. Results: Fifteen patients with stage 3 disease were assessed, five of whom were staged as type $3 \mathrm{~A}$ and ten as $3 \mathrm{~B}$ using the Lichtman stages. According to the Outerbridge classification, the lunate sulcus was the most affected with means of 2.8 at $3 \mathrm{~A}$ and 2.9 at $3 \mathrm{~B}$. Other areas were significantly less affected with means of 1.1 and 1.3 , respectively. Conclusion: Arthroscopic assessment of the wrist could aid in surgical decision making, offering more details on cartilage status in stage 3 Kienböck's disease. Level of Evidence III, Study of nonconsecutive patients, without consistently applied reference "gold" standard.

Keywords: Osteonecrosis. Wrist. Arthroscopy.

\section{RESUMO}

Objetivo: O tratamento da doença de Kienböck é desafiador, e a variabilidade dos resultados, apesar da técnica cirúrgica, mostra que deve haver outros aspectos que influenciam os desfechos. O objetivo deste estudo é determinar, por via artroscópica, o padrão de comprometimento dos ossos do carpo em pacientes com estágio 3 de Lichtman. Método: A artroscopia de punho foi realizada em pacientes com sintomas e evidências de necrose do semilunar à radiografia, com sinais de estágios $3 A$ e 3B. A classificação de Outerbridge foi usada para determinar a condição articular dos ossos do carpo. Resultados: Foram avaliados 15 pacientes com doença em estágio 3, sendo que cinco classificados como tipo 3A e dez como tipo 3B usando os estágios de Lichtman. De acordo com a classificação de Outerbridge, o sulco semilunar foi mais afetado, com médias de 2,8 em 3A e 2,9 em 3B. Outras áreas foram significativamente menos afetadas, com médias de 1,1 e 1,3, respectivamente. Conclusão: A avaliação artroscópica do punho pode auxiliar na tomada de decisão cirúrgica, oferecendo mais detalhes sobre a condição da cartilagem no estágio 3 da doença de Kienböck. Nível de Evidência III, Estudo de pacientes não-consecutivos, sem padrão de referência "ouro" aplicado uniformemente.

Descritores: Osteonecrose. Punho. Artroscopia.

Citation: Rezende MR, Veronesi BA, Abreu MVA, Amariz GAS. Arthroscopic assessment of the wrist with Kienböck's disease. Acta Ortop Bras. [online]. 2018;26(5):286-9. Available from URL: http://www.scielo.br/aob.

\section{INTRODUCTION}

Understanding the etiology and treatment of the osteonecrosis of the lunate or Kienböck disease is still a challenge. However, its natural history, characterized by progressive worsening of pain with changes in carpal dynamics, is well defined, allowing its staging. ${ }^{1,2}$ It was later modified by Lichtman et al. ${ }^{3}$ and Menth-Chari et al., ${ }^{4}$ who defined 4 stages, ranging from incipient signs of necrosis of the lunate to its complete collapse, leading to carpal derangement, and finally arthrosis. The reliability and reproducibility of this classification, based on radiological findings, were confirmed by the work of Szabo et al., ${ }^{2}$ Jafarnia et al., ${ }^{5}$ Goldfarb et al. ${ }^{6}$ and Iwasaki et al. ${ }^{7}$ However, it has been shown that in many cases, a physician may err in the staging of the disease if he considers other factors such as time of onset of the condition, intensity of pain and range of motion. ${ }^{8}$ These findings support the concept that there is a discrepancy between the radiological staging ${ }^{9}$ and the clinical evolution of the patient in Kienböck disease. ${ }^{9}$ We believe there are other changes, not visible in the radiographic examination, which may contribute to the clinical presentation of the patient.

Bain et al. ${ }^{10}$; Bain and Begg ${ }^{11}$ have proposed that arthroscopy may be the complementary method for best staging of the wrist with Kienböck. They have shown that the articular degenerative process is progressive, beginning in the proximal lunate, followed by the distal lunate, the lunate fossa, then the capitate.

All authors declare no potential conflict of interest related to this article.

Study conducted at the Grupo de Mão e Microcirurgia, Instituto de Ortopedia e Traumatologia, Hospital das Clínicas (HC-FMUSP), Faculdade de Medicina, Universidade de São Paulo, São Paulo, SP, Brazil.

Correspondence: Rua Dr. Ovídio Pires de Campos, 333, Cerqueira Cesar, São Paulo, SP, Brazil. 05403-010. marcelo@marcelorosaderezende.com.br 
The lunate does not collapse until stage 3 of Lichtman classification. From stage 3 and on, biomechanical alterations of the carpus, the articular changes of carpal bones become more evident.

It is a belief of the authors of this paper that the knowledge of clinical conditions and articular status of carpal bones, particularly the lunate, may help in the decision making for treatment choice. The aim of this study is to determine, through an arthroscopic approach, the pattern of compromise of carpal bones in Lichtman stage 3 Kienböck disease.

\section{MATERIALS AND METHOD}

This study was approved by the Research Ethics Committee of our institution under No. 043578/2018 and the free and informed consent form was obtained from all subjects.

Fifteen patients who had stage 3 Kienböck disease underwent wrist artroscopy. Five were type 3A and ten were type 3B according to the Lichtman classification. 3,4 The patients ages ranged from 25 to 39 , with an average of 35 . There were 8 males and 7 females. Anterior-posterior and lateral wrist $x$-rays were made in all patients. Wrist range of motion (ROM) was assessed preoperatively. Inclusion criteria: subjects older than 18 years of age, wrist symptoms and avascular necrosis of the lunate Lichtman stage 3 on $x$-ray. Exclusion criteria: patient non-consent and prior wrist surgery. Taking into account Lichtman classification, stage 1 has symptoms of wrist pain without radiological changes, and stage 2 has lunate sclerosis, but no collapse. Stage 3 has lunate collapse without carpal instability (3A) or with instability and scaphoid rotation (3B). In the study by Goldfarb et al. ${ }^{6}$ and Beckenbaugh et al., ${ }^{12}$ it was shown that the most objective way to decide between stages 3A and 3B for classification was through the radio-scaphoid angle. An angle up to 60 degrees was rated as $3 \mathrm{~A}$ and an angle greater than 60 degrees was ranked 3B. In stage 4, collapse and perilunate arthrosis is evident. Each patient underwent wrist arthroscopy followed by a therapeutic procedure. For the arthroscopy, the affected extremity was positioned with the arm supported on the table and the hand distracted towards the ceiling with a $7 \mathrm{~kg}$ weight. Radiocarpal 3,4 and 4,5 portals were used for introduction of the arthroscope and probe, respectively. Radial and ulnar mid-carpal portals were used to view the mid-carpal joint. Assessment of the radio-carpal and mid-carpal joints was performed, with particular attention to the lunate and the articular surfaces around it.

The Outerbridge classification ${ }^{13,14}$ was used to stage chondral lesions: stage 0 for normal cartilage; stage 1 for edematous and softened cartilage; stage 2 for chondral injury in greater depth and fissure, but without subchondral exposure or a diameter greater than $1.5 \mathrm{~cm}$; stage 3 for fissures reaching the subchondral bone in an area greater than $1.5 \mathrm{~cm}$ in diameter; stage 4 for exposure of subchondral bone. Based on arthroscopic findings, a decision to proceed with either partial arthrodesis (scapholunate or scaphocapitate) or total wrist arthrodesis was made. The therapeutic aspect of the technique was not described in this study.

\section{RESULTS}

The scaphoid groove (Figure 1), lunate groove (Figure 2 and 3), radiocarpal and mediocarpal articular surfaces of the lunate (Figure 4), hamate and capitate articular surfaces (Figure 5) were visualized through wrist arthroscopy and correlated with the classification of Outerbridge. The degree of damage of the cartilage of the lunate groove and radiocarpal and mediocarpal articular surfaces of the lunate were evaluated in stages 3A (Figure 6) and 3B (Figure 7) of Kienbock's disease. It showed that the lunar groove was slightly more affected at stage 3B, with a mean value of 2.9 , than in $3 \mathrm{~A}$ (mean 2.8). (Figure 8) Other areas analyzed were significantly less affected with mean values of 1.1 and 1.3 respectively. It is important to remark that both groups have great variability of degrees for cartilage damage.

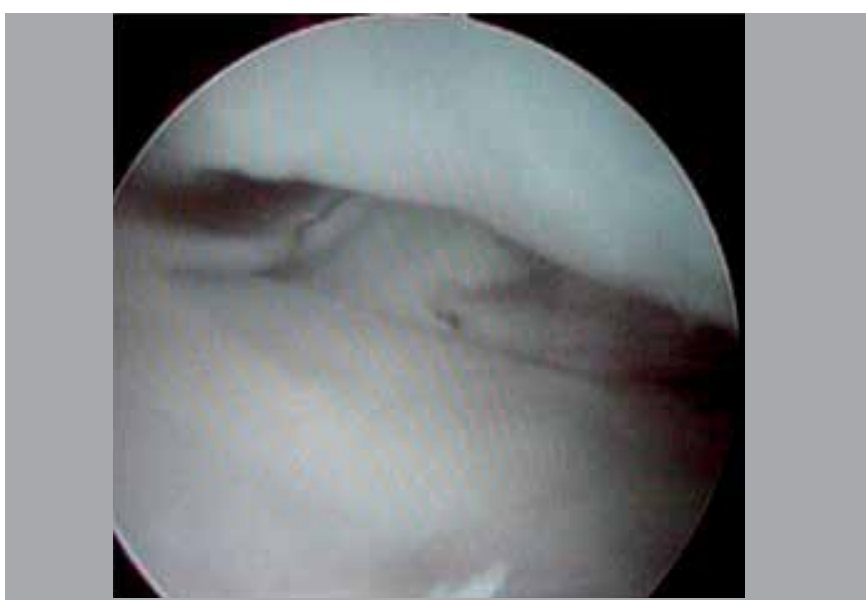

Figure 1. Scaphoid groove view, without chondral damage.

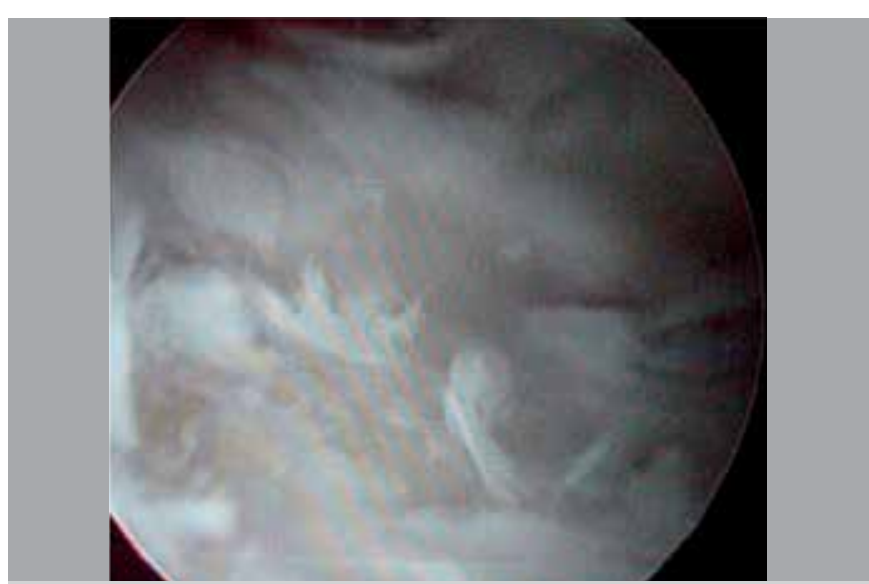

Figure 2. Lunate groove view showing chondral damage (Outerbridge 2).

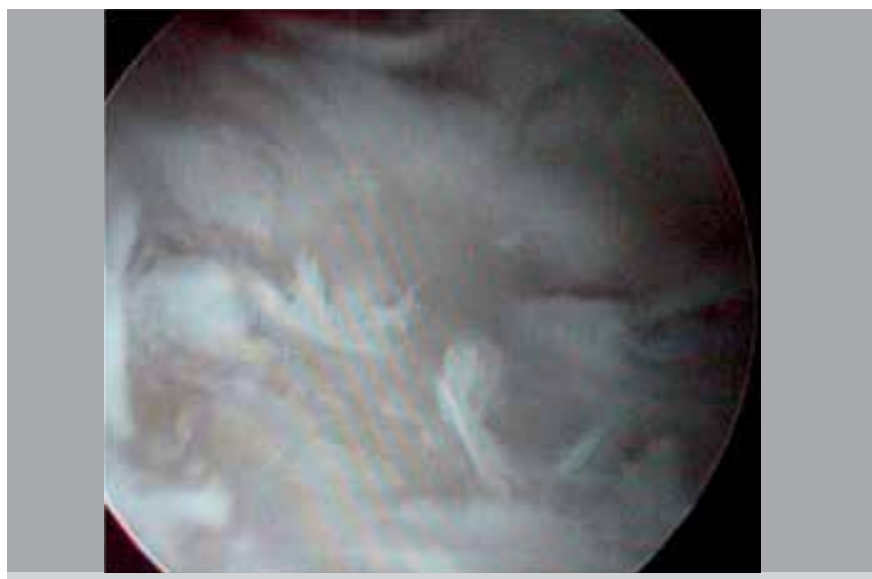

Figure 3. Lunate groove (viewed from radiocarpal joint) showing Outerbridge type 3 chondral defect.

\section{DISCUSSION}

Since its description in 1910,15 Kienbock's disease has been studied from many viewpoints. The etiology of vascular changes of the lunate is still controversial. It has been argued that it is due to fracture, compression factors (ulna minus), ${ }^{7,8}$ or even structural changes of the lunate. ${ }^{12,15,16}$ In fact, after the vascular impairment of the lunate, a sequence of events is observed, ranging from its sclerosis to total collapse and subsequent carpal derangement. 


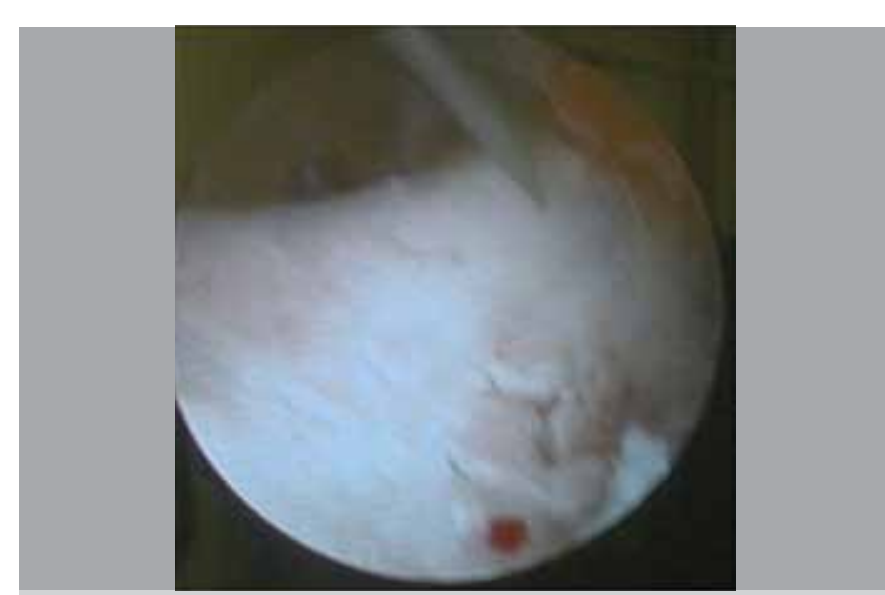

Figure 4. Lunate (viewed from midcarpal joint) showing Outerbridge type 2 defect.

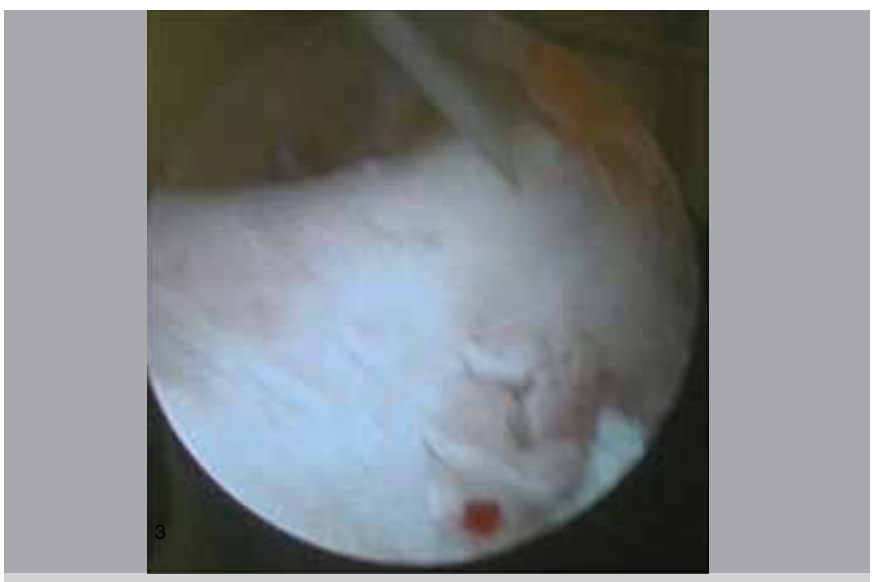

Figure 5. View of the capitate on the left and the hamate on the right, without chondral damage.

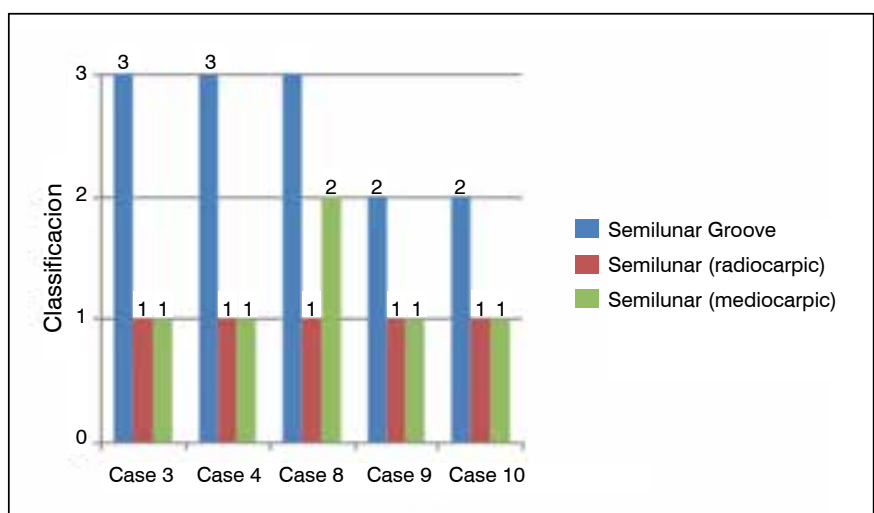

Figure 6. Articular damage degree (Outerbridge classification). The joints are evaluated in group $3 \mathrm{~A}$.

The most widely used classification for Kienbock's disease is Lichtman's, ${ }^{3}$ which charts the progress of the disease by radiological changes in four stages. Jafarnia et al. ${ }^{5}$ has shown great reliability and reproducibility of this classification. Goldfarb et al. ${ }^{6}$ confirmed these facts and emphasized the importance of the radio-scaphoid angle for the differentiation of stages $3 \mathrm{~A}$ and $3 \mathrm{~B}$.

In agreement with Menth-Chiari et al. ${ }^{4}$ we believe that stage 3 is the most difficult stage for surgical decision-making. In addition to lunate collapse, angular alteration of the scaphoid and its

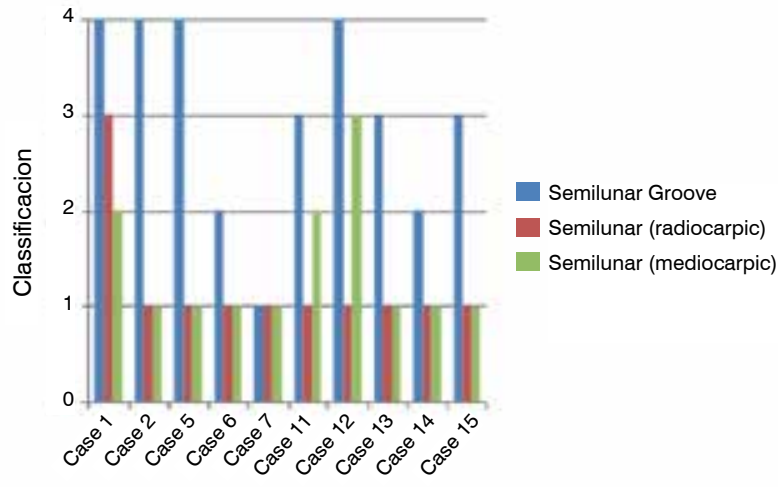

Figure 7. Articular damage degree (Outerbridge classification). The joints are evaluated in group 3B.

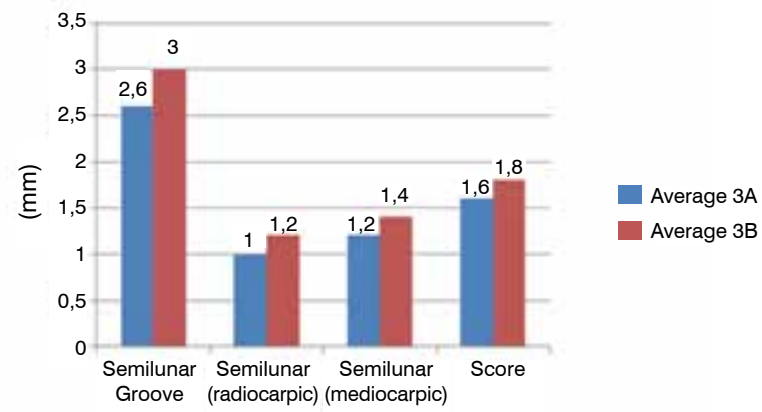

Figure 8. Articular damage degree (Outerbridge classification). The joints are evaluated in group $3 \mathrm{~A}$ and $3 \mathrm{~B}$.

consequences in articular compromise must be considered. As noted by Cameron et al., ${ }^{13}$ we did not observe a direct relationship between the progression of the disease in Lichtman's classification and the clinical worsening of the patient.

We believe that mere radiographic staging does not help to take the best surgical decision. Some departments have treatment protocols according to the stage of the disease, and, therefore, do not take into account the individual characteristics of each patient in surgical planning. We believe it is necessary to make a thorough study of wrist articular alterations which arthroscopy allows.

Few studies have mentioned the use of arthroscopy for staging the degree of articular compromise of the wrist. Bain et al. ${ }^{10}$; Bain and Begg ${ }^{11}$ has presented a proposal for arthroscopic staging of Kienbock's disease. In his studies he has shown that compromise begins in the lunate, mostly in its proximal part. He notes subsequent changes in the lunate fossa and finally capitate changes.

In our study in both stages $3 \mathrm{~A}$ and $3 \mathrm{~B}$, although the degenerative process begins in the lunate, the most important degree of articular compromise occurs in the lunate fossa. We did not observe changes in the articular surface of the capitate, in spite of the fact that it is part of the central row of the carpus. From this result we can conclude that the surgical option of carpectomy, especially in stage 3B, would depend basically on the articular conditions of the lunate fossa since the capitate cartilage is preserved.

Iwasaki et al. ${ }^{7}$ studied the changes of the carpal pressures in Kienbock's disease, and showed that in stage 3, there is a decrease of pressure in the lunate fossa and an increase in the scaphoid 
fossa. In all cases there was preservation of the articular cartilage of the scaphoid fossa, even in 3B cases. The rotatory changes of the scaphoid and the increase in pressure would favor articular surface changes. This finding coincides with those obtained by Bain et al. ${ }^{10}$; Bain and Begg ${ }^{11}$ showed that the articular changes in the scaphoid fossa occur only in stage 4.

Regardless of the absolute values obtained, the patterns of articular compromise were similar in stages $3 \mathrm{~A}$ and $3 \mathrm{~B}$.

First we have observed that the radioscaphoid angle as the widely literature shows is different on stages $3 \mathrm{~A}$ and $3 \mathrm{~B}$, in our study with averages of $50^{\circ}$ and $68^{\circ}$ and, in the statistical study we could demonstrate a direct relationship between the disease and the loss of articular mobility and an indirect relationship between the radioscaphoid angle an joint mobility, both at the expense of loss of extension. An important fact was the great variation of articular compromise, but the range of motion as a role doesn't show significant alteration.

Analyzing our data compared to those obtained by Keith et al. ${ }^{16}$ when studying the natural history of the disease, we have come to believe that there are variable periods of duration for each stage of the disease, as we were able to observe at Figures 6 and 7. This explains possible differences of the degree of articular compromise within the same group, more over Kawoosa et al. ${ }^{8}$ and Altay et al., ${ }^{17}$ showed same results for both $3 \mathrm{~A}$ and $3 \mathrm{~B}$ that reinforces the idea of arthroscopic staging of the wrist in Kienbock's disease, because it gives a much more precise information

For the arthroscopic evaluation we used portals 3 and 4 and the ulnar and radial midcarpal portals, which were sufficient for a correct articular staging, diagnostic arthroscopy is a quick procedure. In a few minutes, it can establish the degree of articular compromise of the wrist.

In our work, we sought to evaluate objectively the articular conditions of the wrist in Kienbock's disease and the use of arthroscopy for correct articular staging provides more data to choose the best surgical procedure.

\section{CONCLUSION}

The best treatment for stage 3 Kienböck disease is controversial. We observed wide variation in the degree of articular compromise and clinical presentation. Therefore, in addition to lunate collapse, the shifting scapholunate angle and its consequences must be considered. Arthroscopic assessment of the wrist could aid in surgical decision making, offering more details about cartilage status.

AUTHORS' CONTRIBUTIONS: Each author contributed individually and significantly to the development of this article. MRR (0000-0003-3441-8117)*: performed the surgeries and contributed to the concept and design of the article; BAV (0000-0002-4694-6112)* and MVAA (0000-0003-4988-7274)*: drafted the text, analyzed the data, conducted the statistical analysis; GASA (0000-0002-6599-4339)*: participated in drafting and revising the text. *ORCID (Open Researcher and Contributor ID).

\section{REFERENCES}

1. Ståhl F. On lunatomalacia (Kienböck's disease): a clinical and roentgenologica study, especially on its pathogenesis and late results of immobilization treatment. Acta Chir Scand. 1947;126(Suppl):1-133.

2. Szabo RM, Greenspan A. Diagnosis and clinical findings of Kienböck's disease. Hand Clin. 1993;9(3):399-408.

3. Lichtman DM, Degnan GG. Staging and its use in the determination of treatment modalities for Kienböck's disease. Hand Clin. 1993;9(3):409-16.

4. Menth-Chiari WA, Poehling GG, Wiesler ER, Ruch DS. Arthroscopic debridement for the treatment of Kienbock's disease. Arthroscopy. 1999 Jan-Feb;15(1):12-9.

5. Jafarnia K, Collins ED, Kohl HW 3rd, Bennett JB, Ilahi OA. Reliability of the Lichtman classification of Kienböck's disease. J Hand Surg Am. 2000;25(3):529-34.

6. Goldfarb CA, Hsu J, Gelberman RH, Boyer MI. The Lichtman classification for Kienböck's disease: an assessment of reliability. J Hand Surg Am. 2003;28(1):74-80.

7. Iwasaki N, Minami A, Miyazawa T, Kaneda K. Force distribution through the wrist joint in patients with different stages of Kienböck's disease: using computed tomography osteoabsorptiometry. J Hand Surg Am. 2000;25(5):870-6.

8. Kawoosa AA, Dhar SA, Mir MR, Butt MF. Distraction osteogenesis for ulnar lengthening in Kienbock's disease. Int Orthop. 2007;31(3):339-44.

9. Bartelmann U, Kalb K, Schmitt R, Fröhner S. Radiologic diagnosis of lunate necrosis. Handchir Mikrochir Plast Chir. 2001;33(6):365-78

10. Bain GI, Richards RS, Roth JH. Wrist arthroscopy. In: Lichtman DM, Alexander AH editors. The wrist and its disorders. 2nd ed. Philadelphia: Sanders; 1997. p. 151-68

11. Bain GI, Begg M. Arthroscopic assessment and classification of Kienbock's disease. Tech Hand Up Extrem Surg. 2006;10(1):8-13.

12. Beckenbaugh RD, Shives TC, Dobyns JH, Linscheid RL. Kienböck's disease: the natural history of Kienböck's disease and consideration of lunate fractures. Clin Orthop Relat Res. 1980;(149):98-106.

13. Cameron ML, Briggs KK, Steadman JR. Reproducibility and reliability of the outerbridge classification for grading chondral lesions of the knee arthroscopically. Am J Sports Med. 2003;31(1):83-6.

14. Outerbridge RE, Dunlop JA. The problem of chondromalacia patellae. Clin Orthop Relat Res. 1975;(110):177-96.

15. Kienböck R. Uber Traumatische Malazie des Mondbeins und ihre Folgezustande: Entartungsformen und Kompressionsfrakturen. Fortschr Roentgenstr. 1910;16:78-115

16. Keith PP, Nuttall D, Trail I. Long-term outcome of nonsurgically managed Kienböck's disease. J Hand Surg Am. 2004;29(1):63-7.

17. Altay T, Kaya A, Karapinar L, Ozturk H, Kayali C. Is radial shortening useful for Litchman stage 3B Kienbock's disease? Int Orthop. 2008;32(6):747-52. 